Rev. Inst. Flor. v. 29 n. 1 p. $71-89$ jun. 2017

http://dx.doi.org/10.24278/2178-5031.201729105

ISSN impresso 0103-2674/on-line 2178-5031

\title{
HERPETOFAUNA DA ESTAÇÃO ECOLÓGICA DE BAURU, UM FRAGMENTO DE MATA ATLÂNTICA NO ESTADO DE SÃO PAULO, BRASIL ${ }^{1}$

\author{
HERPETOFAUNA FROM ESTAÇÃO ECOLÓGICA DE BAURU, \\ A FRAGMENT OF ATLANTIC FOREST IN THE STATE OF SÃO PAULO, BRAZIL
}

\author{
Cybele de Oliveira ARAUJO ${ }^{2,3}$
}

\begin{abstract}
RESUMO - A herpetofauna do estado de São Paulo pode ser considerada a mais conhecida no país. No entanto, ainda existem consideráveis lacunas amostrais, sobretudo em remanescentes de vegetação natural presentes na região central do estado. Nesse contexto, o objetivo deste estudo foi gerar informações sobre a composição, riqueza e abundância de anfíbios e répteis na Estação Ecológica de Bauru, um fragmento de Mata Atlântica presente no centro-oeste do estado de São Paulo. O levantamento das espécies foi conduzido mensalmente de outubro/2007 a março/2008, totalizando 30 dias de inventário. A amostragem foi realizada por meio de armadilhas de interceptação e queda, encontro ocasional, procura auditiva e procura visual. Foram registradas 20 espécies de anfíbios pertencentes a nove gêneros e quatro famílias (Bufonidae, Hylidae, Leptodactylidae e Microhylidae) e oito espécies de répteis pertencentes a oito gêneros e sete famílias (Amphisbaenidae, Dactyloidae, Gymnophthalmidae, Mabuyidae, Teiidae, Dipsadidae e Viperidae). Este estudo contribui para ampliar o conhecimento sobre a diversidade de anfíbios e répteis na Mata Atlântica, um dos hotspots mundiais prioritários para a conservação biológica.
\end{abstract}

Palavras-chave: anfíbios; répteis; inventário; diversidade; conservação.

\begin{abstract}
The herpetofauna of São Paulo state is the best known in Brazil. However, there are still considerable sampling gaps at the natural vegetation remnants present in the central region of the state. The purpose of this study was to obtain information on species composition, species richness and abundance of amphibians and reptiles recorded at Estação Ecológica de Bauru, a fragment of Atlantic Forest in the Midwest region of the state of São Paulo. The inventory was conducted monthly from October/2007 to March/2008, totaling 30 sampling days. Surveys were performed using pitfall traps, incidental encounters and acoustic and visual searches. I recorded 20 amphibian species, belonging to nine genera and four families (Bufonidae, Hylidae, Leptodactylidae e Microhylidae), and eight reptile species belonging to eight genera and seven families (Amphisbaenidae, Dactyloidae, Gymnophthalmidae, Mabuyidae, Teiidae, Dipsadidae and Viperidae). This study expands the knowledge about the diversity of amphibians and reptiles in the Atlantic Forest, a global biodiversity hotspot.
\end{abstract}

Keywords: amphibians; reptiles; inventory; diversity; conservation.

\footnotetext{
${ }^{1}$ Recebido para análise em 15.03.2017. Aceito para publicação em 31.05.2017. 


\section{INTRODUÇÃO}

O Brasil apresenta a maior riqueza de anfíbios do planeta, sendo atualmente conhecidas 1.080 espécies para o território nacional (Segalla et al., 2016). No estado de São Paulo, são registradas 236 espécies de anfíbios, o que corresponde a aproximadamente $22 \%$ da riqueza de espécies encontradas no país (Rossa-Feres et al., 2011). Em relação aos répteis, o Brasil abriga 773 espécies de serpentes, lagartos, anfisbenídeos, quelônios e jacarés (Costa e Bérnils, 2015), sendo descritas um total de 212 espécies de répteis para o estado, o que representa $27 \%$ da diversidade brasileira (Zaher et al., 2011).

A Mata Atlântica, considerada um dos 34 hotspots mundiais prioritários para a conservação biológica (Mittermeier et al., 2004), é o domínio brasileiro que possui a maior riqueza de anfíbios, com 543 espécies descritas, das quais 88\% são endêmicas (Haddad et al., 2013). No estado de São Paulo, é possível identificar um gradiente decrescente na riqueza de anuros partindo das fisionomias de floresta ombrófila presentes no litoral (211 espécies) em direção ao interior, onde predominam as formações de Cerrado e floresta estacional (58 espécies) e a sazonalidade climática é mais acentuada (Araújo et al., 2009; Rossa-Feres et al., 2011).

Processos históricos de uso e ocupação do solo levaram à supressão e fragmentação da cobertura vegetal na Mata Atlântica, restando menos de $12 \%$ de sua extensão original, o que correspondia a $15 \%$ do território brasileiro (Morellato e Haddad, 2000; Ribeiro et al., 2011). Estimativas recentes apontam que esse domínio fitogeográfico se apresenta sob a forma de fragmentos descontínuos, sendo a maior parte $(83,4 \%)$ menor que 50 ha (Ribeiro et al., 2011). Dentre as formações florestais brasileiras, a floresta estacional semidecidual é uma das mais ameaçadas e a que sofreu maior desmatamento, sobretudo em regiões onde a topografia propicia a agropecuária (Leitão Filho, 1987; Durigan et al., 2000; Ribeiro et al., 2011). Alguns autores consideram que sua composição florística é uma transição entre a floresta ombrófila atlântica e o Cerrado, sendo classificada como um subconjunto da flora muito mais diversa da floresta ombrófila e composta por espécies capazes de sobreviver a uma estação seca mais prolongada (Leitão Filho, 1987; Oliveira-Filho e Fontes, 2000; Oliveira, 2006). No entanto, estudos sugerem que essa formação vegetal seja considerada uma unidade fitogeográfica distinta, possuindo um número considerável de táxons endêmicos de plantas, lagartos e anfíbios (Prado, 2000; Werneck e Colli, 2006; Iop et al., 2011; Werneck et al., 2011)

No estado de São Paulo, os remanescentes de Mata Atlântica encontram-se atualmente pulverizados em pequenos fragmentos, exceto pela extensa área contínua de floresta ombrófila densa presente ao longo das serras do Mar e de Paranapiacaba (Kronka et al., 2005). Em relação à floresta estacional semidecidual, restam poucas áreas com extensão superior a 10.000 ha, sendo o Parque Estadual do Morro do Diabo, com cerca de 33.900 ha, a maior área contínua desta formação vegetal no estado (Kronka et al., 2005; Faria e Pires, 2006).

Ainda se conhece pouco sobre a fauna de anfíbios e répteis presentes nas florestas estacionais semideciduais do estado de São Paulo. No entanto, nos últimos anos houve aumento significativo no número de trabalhos publicados sobre a diversidade de anfíbios associados a essa formação vegetal no estado (Araujo et al., 2009; Santos et al., 2009; Brassaloti et al., 2010; Maffei et al., 2011a; Araujo e Almeida-Santos, 2013; Araujo et al., 2013b). A falta de conhecimento é ainda mais acentuada em relação aos répteis, sendo escassos os estudos publicados sobre a diversidade deste grupo faunístico nessa fitofisionomia (Sazima e Haddad, 1992; Dixo et al., 2006) e em outras formações vegetais no interior do estado (Zaher et al., 2011).

Estudos sobre a diversidade da herpetofauna na Mata Atlântica podem gerar informações importantes sobre a composição e distribuição das espécies, servindo de base para a elaboração de medidas efetivas de manejo e conservação deste domínio fitogeográfico. Nesse contexto, o objetivo deste estudo foi fornecer informações sobre a composição, riqueza, abundância e distribuição dos anfíbios e répteis na Estação Ecológica de Bauru, um remanescente de floresta estacional semidecidual presente na porção central do estado de São Paulo. 
ARAUJO, C.O. Herpetofauna da Estação Ecológica de Bauru, São Paulo, Brasil.

\section{MATERIAL E MÉTODOS}

\subsection{Local de Estudo}

A Estação Ecológica de Bauru (22¹9'S, 4904'O; 480-578 m) é uma unidade de conservação localizada no município de Bauru, bacia hidrográfica Tietê-Batalha, estado de São Paulo e apresenta área total de 287,98 ha (Almeida et al., 2010). O clima da região é do tipo Cwa de Köppen, com verões quentes e chuvosos e invernos secos (Almeida et al., 2010). A temperatura média nos meses mais quentes (dezembro a fevereiro) oscila ao redor de $26{ }^{\circ} \mathrm{C}$ e nos meses mais frios (maio a julho) varia em torno de $20{ }^{\circ} \mathrm{C}$ (Almeida et al., 2010). A precipitação média anual é de aproximadamente $1.311 \mathrm{~mm}$, sendo que o período chuvoso ocorre de outubro a março, representando $78 \%$ do total de chuvas e o período seco acontece de abril a setembro (Almeida et al., 2010). A maior média de precipitação mensal ocorre no mês de janeiro $(284,1 \mathrm{~mm})$ e a menor em agosto (21,2 mm) (Almeida et al., 2010). A evapotranspiração real é elevada $(1.110,6 \mathrm{~mm})$, correspondendo a $85 \%$ da precipitação anual e a deficiência hídrica do solo é considerável (143,2 $\mathrm{mm}$ ao ano), estendendo-se de março até outubro (Almeida et al., 2010). A cobertura vegetal dessa estação ecológica é constituída predominantemente pela floresta estacional semidecidual submontana (255 ha; $90 \%$ ) e floresta estacional semidecidual aluvial (15,6 ha; 5,5\%), apresentando também algumas manchas de ecótono entre a floresta estacional e o $\operatorname{Cerrado}(2,7$ ha; $1 \%)$ e pequenas áreas com reflorestamento $(0,7 \%)$ (Souza et al., 2010) (Figura 1).

\subsection{Coleta e Análise dos Dados}

O inventário das espécies foi realizado em seis etapas de campo mensais, com duração de cinco dias cada, totalizando 30 dias de amostragem (outubro/2007 a março/2008). Foram utilizadas armadilhas de interceptação e queda (pitfall traps) interligadas por cercas-guia (drift-fences) (Corn, 1994) em ambientes com diferentes fitofisionomias (Figura 1, Apêndice 1). Adicionalmente, foram realizadas amostragens por meio dos métodos de procura auditiva, procura visual e encontro ocasional (Crump e Scott Jr., 1994; Scott Jr. e Woodward, 1994) nos locais descritos acima e nos sítios reprodutivos utilizados pelos anfíbios, como brejos, córregos, lagoas e várzeas (Figura 1, Apêndice 1).

Foram instaladas 11 linhas de armadilhas (unidades amostrais) compostas por quatro baldes plásticos de 60 litros, totalizando 44 armadilhas, com uma distância aproximada de $500 \mathrm{~m}$ entre linhas (Figura 1, Apêndice 1). Os baldes foram inseridos em buracos cavados no solo, sendo dispostos em linha reta (espaçados 15 metros entre si) e interligados por cercas-guia de aproximadamente $50 \mathrm{~cm}$ de altura. As armadilhas permaneceram abertas por cinco dias consecutivos, em um total de 30 dias de amostragem (esforço amostral $=1.320$ armadilhas). Com o intuito de minimizar a predação dos anfíbios capturados nas armadilhas por vertebrados e invertebrados, foram realizadas inspeções a cada 24 horas, sempre no período da manhã. Foram depositados abrigos em cada uma das armadilhas durante todo o período de amostragem para evitar a morte de indivíduos por dessecação e afogamento (Cechin e Martins, 2000). Foram coletados, no máximo, 10 indivíduos por espécie. Os demais espécimes capturados foram identificados, marcados pela amputação da falange distal do terceiro artelho do membro anterior direito (toe-tipping) (Lüddecke e Amézquita, 1999; Phillott et al., 2007) e liberados próximos ao local de captura (licenças IBAMA/RAN 10423-1 e 13706-1). Esse tipo de marcação (batch mark) foi utilizado para que os indivíduos recapturados nas armadilhas não fossem recontados nas amostragens subsequentes. A relevância desse método de marcação de anuros em estudos populacionais foi apresentada por Corrêa et al. (2013). 


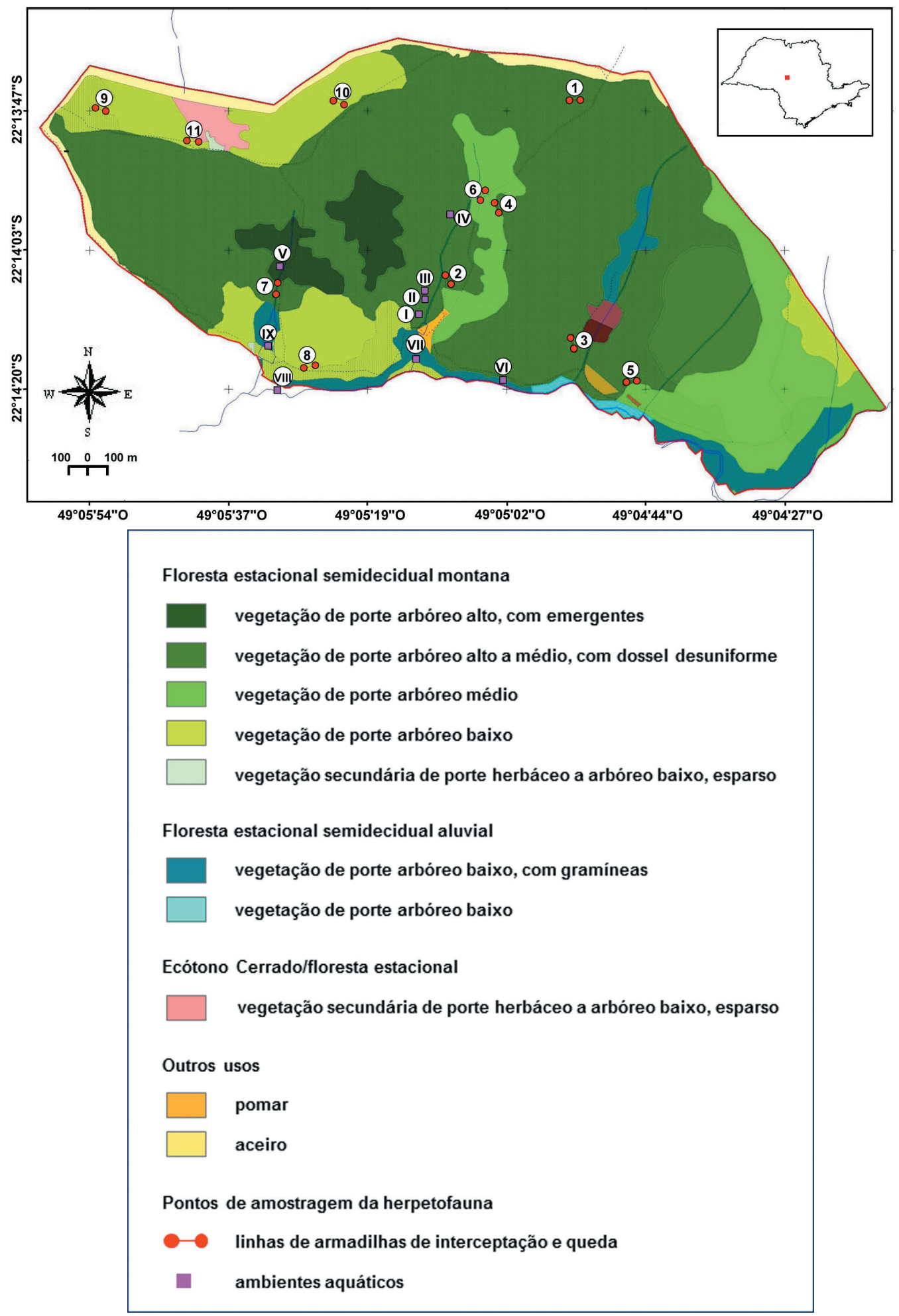

Figura 1. Cobertura vegetal da Estação Ecológica de Bauru, SP e locais de amostragem (pontos em vermelho = linhas de armadilhas de interceptação e queda; pontos em rosa = ambientes aquáticos). $\mathrm{O}$ detalhe à direita apresenta a localização da unidade de conservação no estado de São Paulo. Fonte: modificado de Almeida et al. (2010).

Figure 1. Vegetation of the Estação Ecológica de Bauru, São Paulo state, Brazil and sampled areas (red dots = pitfall trap lines; pink dots $=$ aquatic sites). The detail on the right side represents the location of the conservation unit in the São Paulo state. Source: modified from Almeida et al. (2010). 
ARAUJO, C.O. Herpetofauna da Estação Ecológica de Bauru, São Paulo, Brasil.

A procura auditiva e visual consistiu em censos efetuados no período noturno, sendo examinados os microhábitats acessíveis (e.g., bromélias, folhiço e tronco de árvores) e os sítios aquáticos utilizados pelas espécies de anfíbios durante o período reprodutivo. A amostragem variou entre três e seis horas por noite, resultando em um esforço total de aproximadamente 100 horas de procura. A distância percorrida em cada noite não foi padronizada, no entanto, manteve-se o compromisso de amostrar os nove ambientes aquáticos em cada noite (Figura 1, Apêndice 1). $\mathrm{O}$ método de encontro ocasional consistiu no registro de espécimes encontrados vivos ou mortos, quando não estava sendo executado nenhum tipo de procura. Os espécimes coletados ao longo deste estudo foram identificados por meio de consulta à taxonomistas de cada grupo, comparação com indivíduos tombados nas coleções científicas e consulta à literatura especializada, sendo posteriormente depositados na Coleção de Anfíbios do Instituto de Biociências da Universidade Estadual Paulista, campus de Rio Claro (CFBH) e Coleção Herpetológica do Instituto Butantan (IBSP e CRIB) (Apêndice 2).

A eficiência da amostragem foi avaliada por meio de curvas de rarefação (Gotelli e Colwell, 2001) geradas a partir dos dados de incidência dos anfíbios registrados durante o período de inventário. $\mathrm{O}$ número total de espécies registradas em cada dia foi considerado como uma amostra, totalizando 13 amostras obtidas pela procura auditiva e visual e 30 amostras pelas linhas de armadilhas. Considerando-se os diversos estimadores de riqueza disponíveis, optou-se pela utilização do algoritmo Jackknife de primeira ordem (Magurran, 2004; Walther e Moore, 2005; Hortal et al., 2006). Apesar de alguns autores apontarem que os estimadores não paramétricos apresentam grande dependência da riqueza de espécies observada e, portanto, do número e tamanho das amostras (Melo e Froehlich, 2001; Melo, 2004), ainda assim, a riqueza estimada neste inventário pode fornecer uma base para comparações com outros levantamentos realizados em localidades do interior do estado que utilizaram este estimador de riqueza (e.g., Ribeiro-Júnior e Bertoluci, 2009; Santos et al., 2009; Brassaloti et al., 2010; Araujo e Almeida-Santos, 2011; Valdujo et al., 2011; Araujo e Almeida-Santos, 2013; Araujo et al., 2013a). As análises foram realizadas no programa EstimateS v.9.1.0 com 10.000 aleatorizações (Colwell, 2016).

O status de conservação das espécies foi obtido na lista vermelha internacional de espécies ameaçadas de extinção (International Union for Conservation of Nature - IUCN, 2016), lista nacional oficial de espécies da fauna ameaçadas de extinção (Brasil, 2014) e lista de espécies de vertebrados e invertebrados da fauna silvestre ameaçadas de extinção do estado de São Paulo (São Paulo, 2014).

\section{RESULTADOS E DISCUSSÃO}

\subsection{Composição e Distribuição das Espécies}

Neste levantamento, foram registradas 20 espécies de anfíbios anuros distribuídas em quatro famílias (Bufonidae, Hylidae, Leptodactylidae e Microhylidae), uma espécie de anfisbênia (Amphisbaenidae), cinco espécies de lagartos pertencentes a quatro famílias (Gymnophthalmidae, Polychrotidae, Scincidae e Teiidae) e duas espécies de serpentes pertencentes a duas famílias (Dipsadidae e Viperidae) (Figura 2, Tabelas 1 e 2).

Amostragens realizadas em outras localidades do município de Bauru apontam a presença de quatro espécies de anfíbios que não foram observadas neste estudo: Hypsiboas caingua, Leptodactylus chaquensis, Proceratophrys moratoi e Scinax fuscomarginatus (Rolim, 2010, 2013). $P$. moratoi e $S$. fuscomarginatus são espécies associadas às fitofisionomias abertas de Cerrado (Brasileiro et al., 2005; Araujo et al., 2013a), formações vegetais estas ausentes na Estação Ecológica de Bauru. 


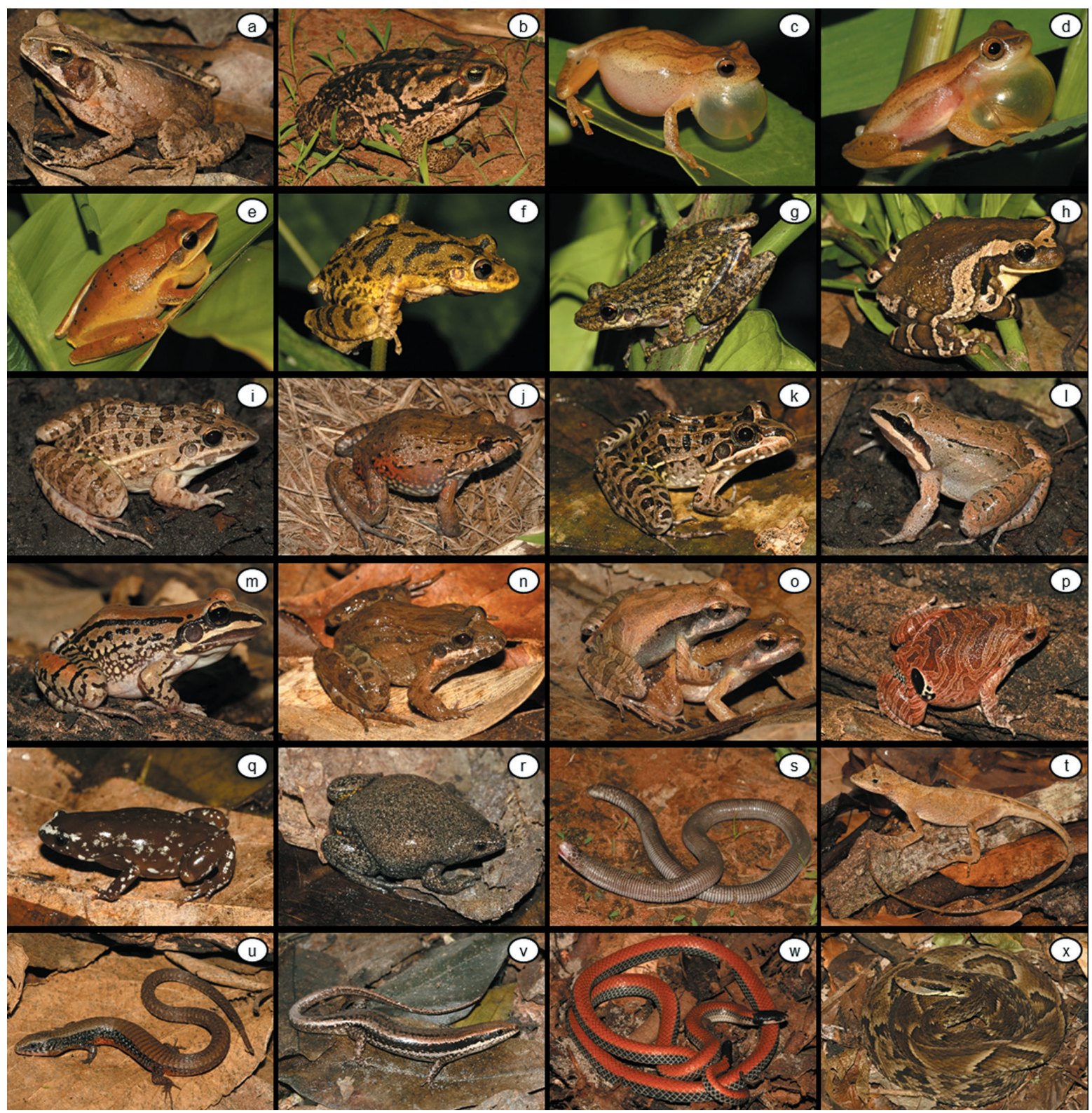

Figura 2. Espécies de anfíbios e répteis amostradas na Estação Ecológica de Bauru, SP. a = Rhinella ornata; $\mathrm{b}=$ Rhinella schneideri; $\mathrm{c}=$ Dendropsophus minutus; $\mathrm{d}=$ Dendropsophus nanus; $\mathrm{e}=$ Hypsiboas albopunctatus; $\mathrm{f}=$ Scinax fuscovarius; $\mathrm{g}=$ Scinax similis; $\mathrm{h}=$ Trachycephalus typhonius; $\mathrm{i}=$ Leptodactylus fuscus; $\mathrm{j}=$ Leptodactylus labyrinthicus $; \mathrm{k}=$ Leptodactylus latrans $; \mathrm{l}=$ Leptodactylus mystaceus; $\mathrm{m}=$ Leptodactylus mystacinus; $\mathrm{n}=$ Leptodactylus podicipinus $; \mathrm{o}=$ Physalaemus cuvieri $; \mathrm{p}=$ Physalaemus nattereri $; \mathrm{q}=$ Chiasmocleis albopunctata; $\mathrm{r}=$ Elachistocleis cesarii; $\mathrm{s}=$ Amphisbaena mertensii $; \mathrm{t}=$ Norops brasiliensis $; \mathrm{u}=$ Colobosaura modesta; $\mathrm{v}=$ Notomabuya frenata $; \mathrm{w}=$ Apostolepis dimidiata $; \mathrm{x}=$ Bothrops jararaca . Todos os indivíduos são da localidade estudada (fotos: Cybele O. Araujo).

Figure 2. Species of amphibians and reptiles sampled at the Estação Ecológica de Bauru, São Paulo state, Brazil. $\mathrm{a}=$ Rhinella ornata $; \mathrm{b}=$ Rhinella schneideri; $\mathrm{c}=$ Dendropsophus minutus; $\mathrm{d}=$ Dendropsophus nanus; $\mathrm{e}=$ Hypsiboas albopunctatus $; \mathrm{f}=$ Scinax fuscovarius $; \mathrm{g}=$ Scinax similis $; \mathrm{h}=$ Trachycephalus typhonius; $\mathrm{i}=$ Leptodactylus fuscus $; \mathrm{j}=$ Leptodactylus labyrinthicus $; \mathrm{k}=$ Leptodactylus latrans; 1 = Leptodactylus mystaceus; $\mathrm{m}=$ Leptodactylus mystacinus $; \mathrm{n}=$ Leptodactylus podicipinus $; \mathrm{o}=$ Physalaemus cuvieri $; \mathrm{p}=$ Physalaemus nattereri; $\mathrm{q}=$ Chiasmocleis albopunctata $; \mathrm{r}=$ Elachistocleis cesarii $; \mathrm{s}=$ Amphisbaena mertensii $; \mathrm{t}=$ Norops brasiliensis; $\mathrm{u}=$ Colobosaura modesta $; \mathrm{v}=$ Notomabuya frenata $; \mathrm{w}=$ Apostolepis dimidiata $; \mathrm{x}=$ Bothrops jararaca. All individuals are from the studied locality (photos: Cybele O. Araujo). 
ARAUJO, C.O. Herpetofauna da Estação Ecológica de Bauru, São Paulo, Brasil.

Tabela 1. Anfíbios da Estação Ecológica de Bauru, SP. Métodos de amostragem: AIQ = armadilhas de interceptação e queda; PA = procura auditiva; PV = procura visual. Locais de captura: linhas de armadilhas (1-11) e ambientes aquáticos (I-IX).

Table 1. Amphibians from Estação Ecológica de Bauru, São Paulo state, Brazil. Sampling methods: AIQ = pitfall traps; $\mathrm{PA}=$ auditory encounters; PV = visual encounters. Capture sites: pitfall traps lines (1-11) and aquatic sites (I-IX).

\begin{tabular}{|c|c|c|}
\hline Ordem/Família/espécie & Método & Linha de armadilha/ambiente aquático \\
\hline \multicolumn{3}{|l|}{ ANURA } \\
\hline \multicolumn{3}{|l|}{ Bufonidae } \\
\hline Rhinella ornata (Spix, 1824) & AIQ, PA & $1,2,3,4,5,6,7,8,9,10 / \mathrm{I}, \mathrm{IV}$ \\
\hline Rhinella schneideri (Werner, 1894) & AIQ, PA, PV & $3,4,6,7,11 / \mathrm{VI}, \mathrm{VII}, \mathrm{VIII}$ \\
\hline \multicolumn{3}{|l|}{ Hylidae } \\
\hline Dendropsophus minutus (Peters, 1872) & $\mathrm{PA}, \mathrm{PV}$ & I, VIII \\
\hline Dendropsophus nanus (Boulenger, 1889) & PA, PV & I, VI, VII, VIII, IX \\
\hline Hypsiboas albopunctatus (Spix, 1824) & $\mathrm{PA}, \mathrm{PV}$ & I, VI, VIII, IX \\
\hline Hypsiboas faber (Wied-Neuwied, 1821) & $\mathrm{PA}, \mathrm{PV}$ & I, VI, VIII \\
\hline Hypsiboas lundii (Burmeister, 1856) & $\mathrm{PA}, \mathrm{PV}$ & I, IV, VI, VII, IX \\
\hline Scinax fuscovarius (A. Lutz, 1925) & PA, PV & I, VI, VIII \\
\hline Scinax similis (Cochran, 1952) & $\mathrm{PA}, \mathrm{PV}$ & VI, VIII \\
\hline Trachycephalus typhonius (Linnaeus, 1758) & PA, PV & I \\
\hline \multicolumn{3}{|l|}{ Leptodactylidae } \\
\hline Leptodactylus fuscus (Schneider, 1799) & AIQ, PA, PV & 2/ VI, VII, VIII, IX \\
\hline Leptodactylus labyrinthicus (Spix, 1824) & $\mathrm{PA}, \mathrm{PV}$ & I, VIII \\
\hline Leptodactylus latrans (Steffen, 1815) & AIQ, PA, PV & 6,10/ VII, VIII \\
\hline Leptodactylus mystaceus (Spix, 1824) & AIQ, PA, PV & $1,2,3,8,9,10,11 / \mathrm{I}, \mathrm{VIII}$ \\
\hline Leptodactylus mystacinus (Burmeister, 1861) & AIQ, PA & $1,2,3,4,5,7,8,9,10,11 / \mathrm{I}, \mathrm{VI}, \mathrm{VIII}$ \\
\hline Leptodactylus podicipinus (Cope, 1862) & AIQ, PA, PV & $1,2,3,4,5,6,7,8,9,10,11 / \mathrm{I}, \mathrm{VI}, \mathrm{VII}, \mathrm{VIII}$ \\
\hline Physalaemus cuvieri Fitzinger, 1826 & AIQ, PA & $2,3,4,5,6,7,8,9,11 / \mathrm{I}, \mathrm{VI}, \mathrm{VII}, \mathrm{VIII}$ \\
\hline Physalaemus nattereri (Steindachner, 1863) & AIQ, PA & $1,2,3,4,5,6,7,8,9,10,11 / \mathrm{I}, \mathrm{VI}, \mathrm{VIII}$ \\
\hline \multicolumn{3}{|l|}{ Microhylidae } \\
\hline Chiasmocleis albopunctata (Boettger, 1885) & AIQ, PA & $2,3,4,5,6,7,8 / \mathrm{I}$ \\
\hline Elachistocleis cesarii (Miranda Ribeiro, 1920) & AIQ, PA & $1,5,11 / \mathrm{I}, \mathrm{VI}, \mathrm{VIII}$ \\
\hline
\end{tabular}

Tabela 2. Répteis da Estação Ecológica de Bauru, SP. Métodos de amostragem: AIQ = armadilhas de interceptação e queda; $\mathrm{EO}=$ encontro ocasional. Locais de captura: linhas de armadilhas (1-11).

Table 2. Reptiles from Estação Ecológica de Bauru, São Paulo state, Brazil. Sampling methods: AIQ = pitfall traps; $\mathrm{EO}=$ incidental encounter. Capture sites: pitfall traps lines (1-11).

\begin{tabular}{lll}
\hline Ordem/Família/espécie & Método & Linha de armadilha \\
\hline SQUAMATA & & \\
Amphisbaenidae & AIQ & 1,9
\end{tabular}

continua to be continued 
ARAUJO, C.O. Herpetofauna da Estação Ecológica de Bauru, São Paulo, Brasil.

continuação - Tabela 2

continuation - Table 2

\begin{tabular}{lll}
\hline Ordem/Família/espécie & Método & Linha de armadilha \\
\hline $\begin{array}{l}\text { Dactyloidae } \\
\text { Norops brasiliensis (Vanzolini e Williams, 1970) }\end{array}$ & AIQ & 1,4 \\
$\begin{array}{l}\text { Gymnophthalmidae } \\
\begin{array}{l}\text { Colobosaura modesta (Reinhardt e Luetken, 1862) } \\
\text { Mabuyidae }\end{array}\end{array}$ AIQ & $1,2,3,4,6,8,9,10,11$ \\
$\begin{array}{l}\text { Notomabuya frenata (Cope, 1862) } \\
\text { Teiidae }\end{array}$ & AIQ & $1,2,3,4,5,6,10,11$ \\
$\begin{array}{l}\text { Ameiva ameiva ameiva (Linnaeus, 1758) } \\
\text { Salvator merianae (Duméril e Bibron, 1839) }\end{array}$ & EO & - \\
$\begin{array}{l}\text { Dipsadidae } \\
\text { Apostolepis dimidiata (Jan, 1862) }\end{array}$ & EO & - \\
$\begin{array}{l}\text { Viperidae } \\
\text { Bothrops jararaca } \text { (Wied, 1824) }\end{array}$ & EO & 4 \\
\hline
\end{tabular}

A maior parte dos anfíbios registrados (65\%) apresenta ampla distribuição geográfica, sendo comumente encontradas em várias regiões do Brasil como Dendropsophus minutus, D. nanus, Hypsiboas albopunctatus, Leptodactylus fuscus, L. labyrinthicus, L. latrans, L. mystaceus, L. mystacinus, L. podicipinus, Physalaemus cuvieri, Rhinella schneideri, Scinax fuscovarius e Trachycephalus typhonius (Valdujo et al., 2012; Haddad et al., 2013; Frost, 2017). Já outros anfíbios observados, estão fortemente associados ao domínio do Cerrado como Hypsiboas lundii, espécie típica de formações florestais que ocorre em localidades de floresta estacional no estado de São Paulo (Araujo et al., 2009; Maffei et al., 2011a; Rolim, 2013; Maffei et al., 2015) e Chiasmocleis albopunctata e Physalaemus nattereri, que apresentam grande dependência das formações vegetais abertas presentes neste domínio (Uetanabaro et al., 2008; Valdujo et al., 2012). Apenas uma espécie, Rhinella ornata, exibe distribuição geográfica restrita a remanescentes de Mata Atlântica presentes em alguns estados do sul e sudeste do Brasil (Haddad et al., 2013; Frost, 2017).

Em relação aos répteis, os lagartos Colobosaura modesta e Norops brasiliensis ocorrem frequentemente associados ao Cerrado, estando presentes em uma faixa central que se estende do contato com a Amazônia até o estado de São Paulo (Vanzolini e Williams, 1970;
Nogueira, 2006; Freire et al., 2012). Essas espécies, juntamente com o lagarto Notomabuya frenata, são observadas nas formações florestais de Cerrado (mata de galeria, cerradão e cerrado denso) e também em localidades de floresta estacional (Nogueira, 2006; Araujo, 2011; Araujo e Almeida-Santos, 2011; Araujo et al., 2014). Os lagartos Ameiva ameiva ameiva, N. frenata e Salvator merianae apresentam ampla distribuição pelo território brasileiro (Nogueira, 2006), sendo que $A$. ameiva ameiva e $S$. merianae podem ser consideradas mais generalistas no uso do hábitat, ocupando uma extensa gama de ambientes que incluem formações abertas e florestais de Cerrado, floresta estacional e também áreas alteradas pelo homem (Nogueira, 2006; Thomé, 2006; Araujo e Almeida-Santos, 2011; Araujo et al., 2014). A espécie Amphisbaena mertensii, no Brasil, é encontrada nas regiões centro-oeste, sudeste e sul (Ribeiro et al., 2007; Silveira et al., 2012). Considerando as serpentes, Apostolepis dimidiata possui distribuição geográfica mais restrita, sendo registrada no país em localidades do estado de São Paulo e também nos estados do Mato Grosso do Sul, Minas Gerais e Paraná (Nogueira et al., 2012) e Bothrops jararaca está associada à Mata Atlântica, ocorrendo nas formações florestais e áreas antrópicas do centro-oeste, sudeste e sul do Brasil (Sazima, 1992; Campbell e Lamar, 2004). 
ARAUJO, C.O. Herpetofauna da Estação Ecológica de Bauru, São Paulo, Brasil.

Das espécies amostradas neste estudo, o lagarto $N$. brasiliensis é citado na lista de espécies de vertebrados e invertebrados da fauna silvestre ameaçadas de extinção do estado de São Paulo (São Paulo, 2014).

\subsection{Riqueza e Abundância das Espécies}

A riqueza de espécies de anfíbios observada na Estação Ecológica de Bauru (20 espécies) mostrou-se superior às registradas em outras localidades no município de Bauru, como o Jardim Botânico (18 espécies) e o Instituto Lauro Souza Lima (14 espécies), e inferior a outras unidades de conservação que apresentam predomínio de floresta estacional semidecidual, como as estações ecológicas de Angatuba (31 espécies) e Caetetus (34 espécies) e os parques estaduais das Furnas do Bom Jesus (24 espécies) e Morro do Diabo (28 espécies) (Araujo et al., 2009; Santos et al., 2009; Brassaloti et al., 2010; Araujo e Almeida-Santos, 2013; Rolim, 2013). Considerando os répteis, não existem inventários realizados na região de Bauru disponíveis na literatura científica. Em relação aos lagartos, a riqueza de espécies obtida neste estudo (cinco) é similar à encontrada na Floresta Estadual de Pederneiras, localizada em município vizinho a Bauru, e inferior a outras unidades de conservação de floresta estacional no estado, como a Estação Ecológica de Jataí (nove espécies) e o Parque Estadual do Morro do Diabo (oito espécies) (Dixo et al., 2006; Figueiredo, 2012; Serrano Filho, 2012). A riqueza de espécies de serpentes verificada neste inventário foi incipiente e inviabiliza qualquer tipo de comparação com outras localidades.

Os ambientes aquáticos que apresentaram maior riqueza de espécies de anfíbios foram a lagoa temporária na borda da mata (I) e o córrego na borda da mata e poças temporárias (VIII), ambos exibindo uma riqueza de 16 espécies (Figura 1, Tabela 1). Em contrapartida, nas poças temporárias (II e III) e riacho (V), presentes no interior da mata, não foi encontrada nenhuma espécie (Figura 1).
A maior parte das espécies de anfíbios foi observada em atividade reprodutiva nos corpos d'água lênticos em locais abertos, sendo que apenas $R$. ornata e $H$. lundii utilizaram um corpo d'água lótico no interior da mata (IV) (Figura 1). Padrão semelhante no uso do hábitat foi verificado em outras localidades no estado, que apresentam ecótono entre formações de Cerrado e floresta estacional semidecidual (Vasconcelos e Rossa-Feres, 2005; Araujo et al., 2009; Araujo e Almeida-Santos, 2011; Maffei et al., 2011b; Araujo e Almeida-Santos, 2013). L. latrans foi a única espécie de anfíbio que não foi observada em atividade de vocalização durante o período de amostragem.

As curvas de rarefação para 13 dias de amostragem por procura auditiva e visual para os anfíbios e 30 dias de amostragem por armadilhas de interceptação e queda para os anfíbios e répteis não atingiram uma assíntota. Contudo, as curvas apresentaram tendência à estabilização, indicando que possivelmente a maior parte das espécies foi registrada durante este estudo (Figura 3).

$\mathrm{O}$ estimador de riqueza Jackknife I não indicou diferenças entre as riquezas de anfíbios e répteis estimadas e observadas obtidas pelos diferentes métodos de amostragem (Figura 3). Todas as espécies de anfíbios registradas (20 espécies) foram amostradas por meio da procura auditiva e visual nos ambientes aquáticos utilizados pelas espécies durante o período reprodutivo, sendo que as espécies da família Hylidae (oito) foram observadas exclusivamente por estes métodos (Tabela 1). Nas armadilhas de interceptação e queda foram capturados 531 indivíduos, sendo 483 anfíbios (11 espécies), 44 lagartos (três espécies), três anfisbênias (uma espécie) e uma serpente (Figura 4). As três espécies de anfíbios mais frequentes foram Physalaemus cuvieri (22,4\%), Leptodactylus podicipinus (19,9\%) e Rhinella ornata (19,5\%), correspondendo juntas a mais da metade dos anfíbios capturados (61,8\%) (Figura 4). Entre os répteis, ocorreu forte dominância dos lagartos Colobosaura modesta (50\%) e Notomabuya frenata $(35,4 \%)$ (Figura 4). 


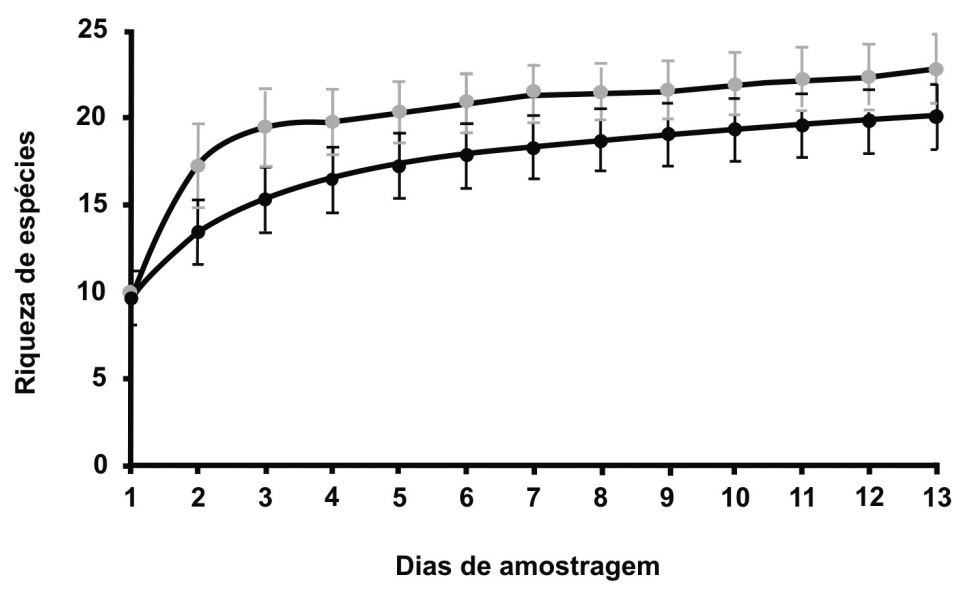

(a)

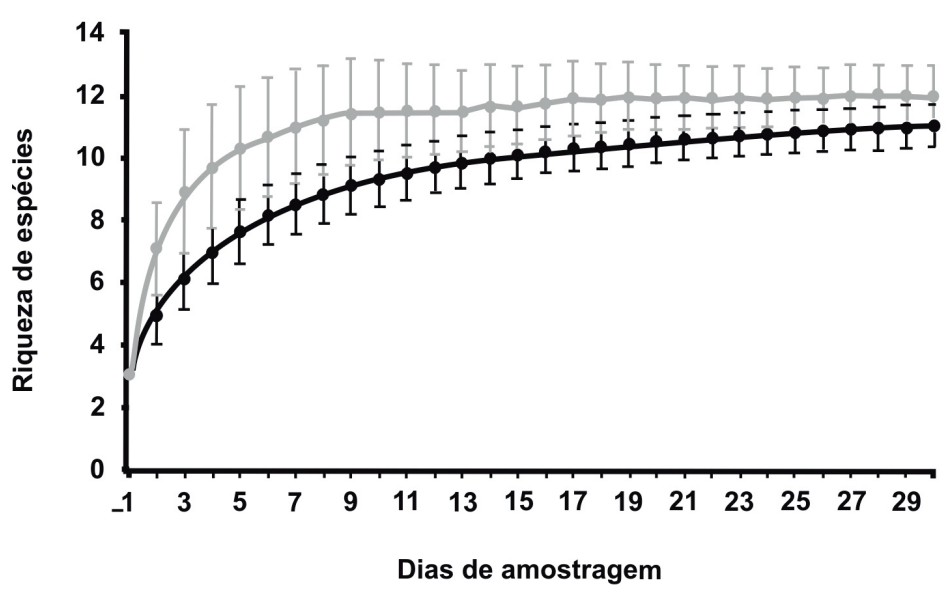

(b)

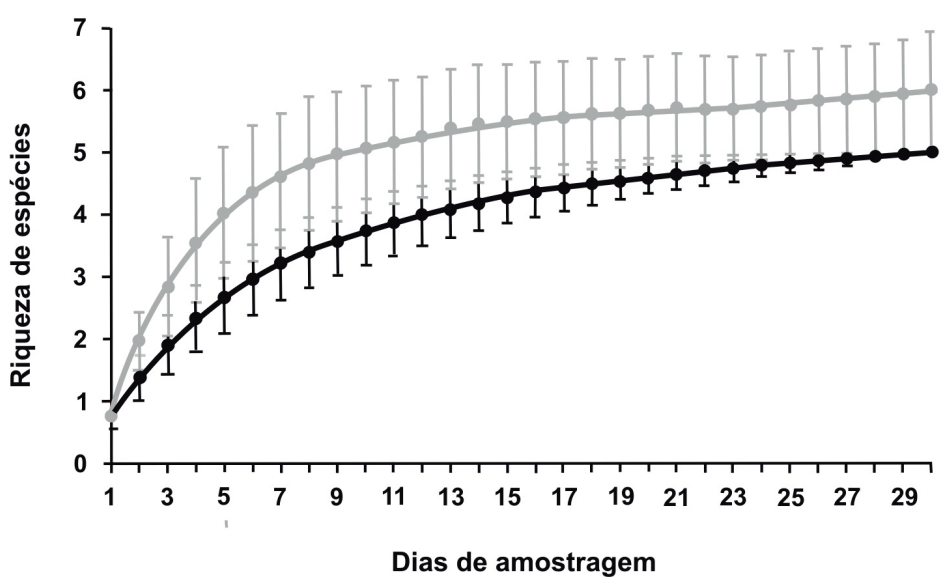

(c)

Figura 3. Curvas de rarefação representando a riqueza de espécies observada (linha preta) e estimada pelo estimador Jackknife I (linha cinza) para 13 dias de amostragem por procura auditiva e visual para os anfíbios (a) e 30 dias de amostragem por armadilhas de interceptação e queda para os anfíbios (b) e répteis (c) na Estação Ecológica de Bauru, SP. As barras verticais correspondem aos desvios-padrão da riqueza de espécies observada e estimada.

Figure 3. Rarefaction curves representing the species richness observed (black line) and estimated by Jackknife I estimator (gray line) for 13 sampling days using acoustic and visual searches for the amphibians (a) and 30 days of sampling by pitfall traps for amphibians (b) and reptiles (c) at the Estação Ecológica de Bauru, São Paulo state, Brazil. Vertical bars represent the standard deviations of species richness observed and estimated. 

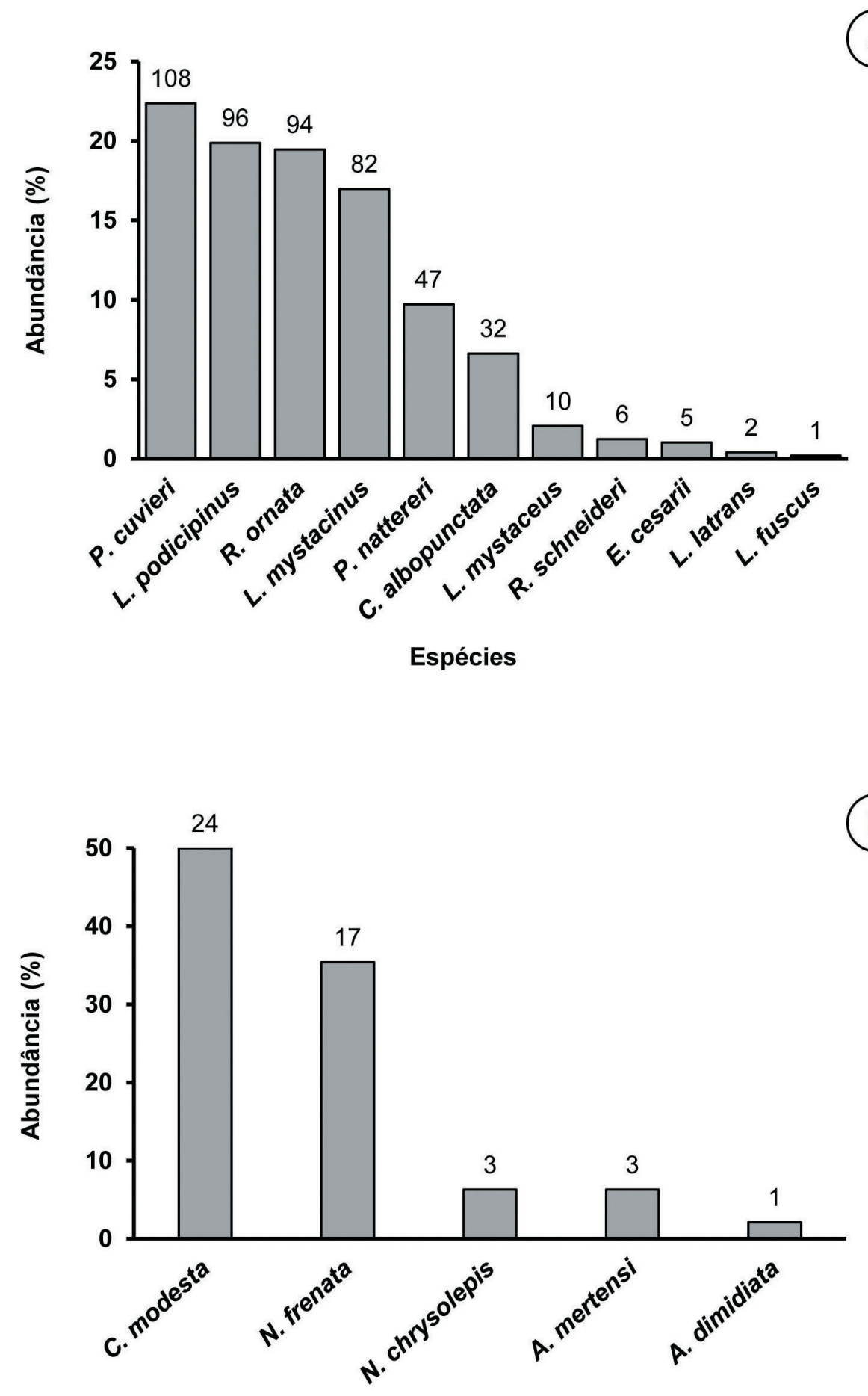

\section{Espécies}

Figura 4. Abundância relativa de anfíbios (a) e répteis (b) amostrados por armadilhas de interceptação e queda na Estação Ecológica de Bauru, SP. Os valores sobre as barras representam o número de indivíduos registrados para cada espécie (número total de indivíduos: anfíbios $=483$; répteis $=48$ ).

Figure 4. Relative abundance of amphibians (a) and reptiles (b) sampled by pitfall traps at the Estação Ecológica de Bauru, São Paulo state, Brazil. The values on the bars represent the number of individuals recorded for each species (total number of individuals: amphibians $=483$; reptiles $=48$ ). 
As armadilhas de interceptação e queda são essenciais para a amostragem de espécies de anfíbios e répteis que apresentam hábitos terrestres, subterrâneos e criptozóicos, que são mais difíceis de serem detectadas pelos métodos tradicionais de procura visual (Cechin e Martins, 2000). Neste estudo, cinco das oito espécies de répteis registradas na localidade foram capturadas exclusivamente pelo método de amostragem passiva. É importante destacar que existem limitações inerentes a cada método e apenas a utilização de métodos complementares (amostragem ativa e passiva) propicia a obtenção de listas de espécies mais completas (Silva, 2010; Silveira et al., 2010). Embora os custos financeiros e o esforço empregado na instalação e manutenção das armadilhas de interceptação e queda sejam mais elevados que os necessários para a realização da procura auditiva e visual (Corn, 1994; Cechin e Martins, 2000), é desejável que a amostragem passiva seja empregada em inventários da herpetofauna. Isto porque, além de permitir a amostragem simultânea de diversos locais, este método permite a obtenção de dados padronizados de riqueza e abundância das espécies, o que favorece comparações mais confiáveis entre diferentes localidades (Silveira et al., 2010).

Apesar do pequeno tamanho dessa estação ecológica (284,23 hectares) e da amostragem realizada demonstrar uma riqueza de espécies de anfíbios e répteis inferior a outras localidades de floresta estacional semidecdual no estado de São Paulo, é importante ressaltar que cada fragmento florestal preservado, por menor que seja, é vital para a manutenção destes grupos faunísticos no interior do estado. A falta de ações realistas e eficazes para a conservação, recuperação e conexão dos remanescentes dessa formação vegetal no estado contribui para o isolamento dessas populações, o que prejudica o fluxo contínuo entre os indivíduos e a diversidade genética, essenciais para garantir metapopulações viáveis (Hanski, 1998).

Considerando que a herpetofauna de uma porção significativa do país permanece pouco amostrada e estudos realizados no Cerrado e Mata Atlântica preveem em um cenário de mudanças climáticas alterações na disponibilidade de áreas adequadas para ocorrência de muitas espécies de anfíbios, em especial as espécies endêmicas e especialistas no uso do hábitat (Haddad et al., 2008; Silvano, 2011), torna-se imprescindível a realização de inventários e estudos padronizados de monitoramento das espécies em localidades que se mantêm como lacunas amostrais. Os dados obtidos nesse tipo de pesquisa contribuem de maneira inequívoca para uma avaliação mais adequada do status de conservação das espécies, declínios populacionais e extinções locais, informações estas indispensáveis para a elaboração de medidas efetivas de manejo e conservação das espécies (Verdade et al., 2012). Ainda pouco se conhece sobre a herpetofauna presente nas florestas estacionais do estado de São Paulo, o que inclui a porção central do estado (Rossa-Feres et al., 2011; Zaher et al., 2011). Nesse sentido, este estudo contribui para a ampliação do conhecimento dessas taxocenoses ao gerar informações sobre a diversidade de anfíbios e répteis de uma localidade de floresta estacional semidecidual presente no município de Bauru, região central do estado.

\section{AGRADECIMENTOS}

Sou grata à Eliana R. de Almeida e à Maria Teresa Z. Toniato, responsáveis pelo Plano de Manejo da Estação Ecológica de Bauru e aos funcionários desta unidade de conservação pelo grande apoio logístico e auxílio durante os trabalhos de campo, ao Célio F. B. Haddad, Miguel T. Rodrigues e Valdir Germano pela contribuição na identificação dos espécimes de anfíbios e répteis, ao Instituto Florestal pelo suporte financeiro e aos revisores anônimos pelas sugestões que aprimoraram este artigo.

\section{REFERÊNCIAS BIBLIOGRÁFICAS}

ALMEIDA, E.R.; TONIATO, M.T.Z; DURIGAN, G. Plano de Manejo da Estação Ecológica de Bauru. São Paulo: Fundação Florestal/SEMA, 2010. 200 p.

ARAUJO, C.O.; CONDEZ, T.H.; SAWAYA, R.J. Anfíbios anuros do Parque Estadual das Furnas do Bom Jesus, Sudeste do Brasil, e suas relações com outras taxocenoses no Brasil. Biota Neotropica, v. 9, n. 2, p. 77-98, 2009. 
ARAUJO, C.O. Herpetofauna da Estação Ecológica de Bauru, São Paulo, Brasil.

ARAUJO, C.O. Squamata, Polychrotidae, Anolis chrysolepis Duméril and Bibron, 1837: distribution extension. Check List, v. 7, n. 3, p. $385-387,2011$.

; ALMEIDA-SANTOS, S.M. Herpetofauna de um remanescente de Cerrado no estado de São Paulo. Biota Neotropica, v. 11, n. 3, p. 47-62, 2011.

.; ALMEIDA-SANTOS, S.M. Composição, riqueza e abundância de anuros em um remanescente de Cerrado e Mata Atlântica no estado de São Paulo. Biota Neotropica, v. 13, n. 1, p. 265-275, 2013.

\section{; CORRÊA, D.T.; ALMEIDA-SANTOS,}

S.M. Anuros da Estação Ecológica de Santa Bárbara, um remanescente de formações abertas de Cerrado no estado de São Paulo. Biota Neotropica, v. 13, n. 3, p. 230-240, 2013a.

; MATSUKUMA, C.K.; ALMEIDA-SANTOS, S.M. Composição taxonômica e distribuição de anuros no Alto e Médio Paranapanema, estado de São Paulo. Biota Neotropica, v. 13, n. 3, p. 241-258, 2013b.

et al. Lizards from Estação Ecológica de Santa Bárbara, a remnant of Cerrado in the state of São Paulo, Brazil. Check List, v. 10, n. 5, p. 1038-1043, 2014.

ARAÚJO, O.G.S. et al. The amphibians of São Paulo State. Biota Neotropica, v. 9, n. 4, p. 197-209, 2009.

BRASIL. Portaria $n^{\circ} 444$, de 17 de dezembro de 2014. Lista Nacional Oficial de Espécies da Fauna Ameaçadas de Extinção. Diário Oficial da União, n. 245, 18 dez. 2014. Seção I, p. 121-126.

BRASILEIRO, C.A. et al. Amphibians of an open Cerrado fragment in southeastern Brazil.

Biota Neotropica, v. 5, n. 2, p. 1-17, 2005.
BRASSALOTI, R.A.; ROSSA-FERES, D.C.; BERTOLUCI, J. Anurofauna da Floresta Estacional Semidecidual da Estação Ecológica dos Caetetus, Sudeste do Brasil. Biota Neotropica, v. 10, n. 1, p. 275-292, 2010.

CAMPBELL, J.A.; LAMAR, W.W. The venomous reptiles of the Western hemisphere. Ithaca: Cornell University Press, 2004. 870 p.

CECHIN, S.Z.; MARTINS, M. Eficiência de armadilhas de queda (Pitfall traps) em amostragens de anfíbios e répteis no Brasil. Revista Brasileira de Zoologia, v. 17, n. 3, p. 729-749, 2000.

COLWELL, R.K. EstimateS: statistical estimation of species richness and shared species from samples version 9. 1. 0., 2016. Disponível em: $<$ http://viceroy.eeb.uconn.edu/estimates/index.html $>$. Acesso em: 14 fev. 2017.

CORN, P.S. Straight-line drift-fences and pitfall traps. In: HEYER, W.R. et al. (Ed.). Measuring and monitoring biological diversity: standard methods for amphibians. Washington, D.C.: Smithsonian Institution Press, 1994. p. 109-117.

CORRÊA, D.T. et al. Population declines: toe-clipping vital to amphibian research. Nature, v. 493, n. 7432, p. 304-305, 2013.

COSTA, H.C.; BÉRNILS, R.S. Répteis brasileiros: lista de espécies. Herpetologia Brasileira, v. 4, n. 3, p. 75-93, 2015.

CRUMP, M.L.; SCOTT JR., N.J. Standard techniques for inventory and monitoring. In: HEYER, W.R. et al. (Ed.). Measuring and monitoring biological diversity: standard methods for amphibians. Washington, D.C.: Smithsonian Institution Press, 1994. p. 84-92.

DIXO, M.; FUENTES, R.A.G.; BRISOLLA, G. Anfíbios e répteis. In: FARIA, H.H.; PIRES, A.S. (Ed.). Parque Estadual do Morro do Diabo: plano de manejo. Santa Cruz do Rio Pardo: Viena, 2006. p. 138-146. 
ARAUJO, C.O. Herpetofauna da Estação Ecológica de Bauru, São Paulo, Brasil.

DURIGAN, G. et. al. Estrutura e diversidade do componente arbóreo da floresta na Estação Ecológica dos Caetetus, Gália, SP. Revista Brasileira de Botânica, v. 23, n. 4, p. 371-383, 2000.

FARIA, H.H.; PIRES, A.S. Parque Estadual do Morro do Diabo: plano de manejo. Santa Cruz do Rio Pardo: Viena, 2006. 311 p.

FIGUEIREDO, C.C. Levantamento de lagartos (Squamata, Sauria) na Floresta Estadual de Pederneiras (SP). 2012. 35 f. Trabalho de Conclusão de Curso - Centro de Ciências da Saúde, Universidade do Sagrado Coração, Bauru.

FREIRE, E.M.X; JORGE, J.S.; RIBEIRO, L.B. First record of Colobosaura modesta (Reinhardt and Lütken, 1862) (Squamata: Gymnophthalmidae) to the Cariri region, state of Ceará, Brazil, with a map of its geographical distribution. Check List, v. 8, n. 5, p. $970-972,2012$.

FROST, D.R. Amphibian species of the world: an online reference, version 6.0. New York: American Museum of Natural History, 2017. Disponível em: $<$ http://research.amnh.org/herpetology/ amphibia/index.html>. Acesso em: 19 maio 2017.

GOTELLI, N.J.; COLWELL, R.K. Quantifying biodiversity: procedures and pitfalls in the measurement and comparison of species richness. Ecology Letters, v. 4, n. 4, p. 379-391, 2001.

HADDAD， C.F.B.; GIOVANELLI， J.G.R.; ALEXANDRINO, J. O aquecimento global e seus efeitos na distribuição e declínios dos anfíbios. In: BUCKERIDGE, M.S. (Ed.). Biologia e mudanças climáticas no Brasil. São Carlos: RiMa, 2008. p. 195-206.

. et al. Guia dos anfíbios da Mata Atlântica: diversidade e biologia. São Paulo: Anolis Books, 2013. $543 \mathrm{p}$.

HANSKI, I. Metapopulation dynamics. Nature, v. 396, n. 6706, p. 41-49, 1998.

HORTAL, J.; BORGES, P.A.V.; GASPARE, C. Evaluating the performance of species richness estimators: sensitivity to sample grain size. Journal of Animal Ecology, v. 75, n. 1, p. 274-287, 2006.
INTERNATIONAL UNION FOR CONSERVATION OF NATURE - IUCN. The IUCN red list of threatened species, version 2016-3. Cambridge: International Union for Conservation of Nature and Natural Resources, 2016. Disponível em: $<$ http://www.iucnredlist.org>. Acesso em: 8 mar. 2017.

IOP, S. et al. Anurans of Turvo State Park: testing the validity of Seasonal Forest as a new biome in Brazil. Journal of Natural History, v. 45, n. 39-40, p. 2443-2461, 2011.

KRONKA, F.J.N. et al. Inventário florestal da vegetação natural do estado de São Paulo. São Paulo: Instituto Florestal: Imprensa Oficial, 2005. 200 p.

LEITÃO FILHO, H.F. Considerações sobre a florística de florestas tropicais e sub-tropicais do Brasil. IPEF, v. 35, p. 41-46, 1987.

LÜDDECKE, H.; AMÉZQUITA, A. Assessment of disc clipping on the survival and behavior of the Andean Frog Hyla labialis. Copeia, v. 1999, n. 3, p. 824-830, 1999.

MAFFEI, F.; UBAID, F.K.; JIM, J. Anfíbios: Fazenda Rio Claro, Lençóis Paulista, SP, Brasil. Bauru: Canal6, 2011a. 128 p.

. Anurofauna em área de cerrado aberto no município de Borebi, estado de São Paulo, Sudeste do Brasil: uso do habitat, abundância e variação sazonal. Biota Neotropica, v. 11, n. 2, p. 202-213, 2011b.

et al. Anurans of the Agudos and Jaú municipalities, state of São Paulo, southeastern Brazil. Check List, v. 11, n. 3, p. 1-7, 2015.

MAGURRAN, A.E. Measuring biological diversity. Oxford: Blackwell Publishing Company, 2004. 256 p.

MELO, A.S. A critique of the use of jackknife and related non-parametric techniques to estimate species richness. Community Ecology, v. 5, n. 2, p. 149-157, 2004. 
ARAUJO, C.O. Herpetofauna da Estação Ecológica de Bauru, São Paulo, Brasil.

MELO, A.S.; FROEHLICH, C.G. Evaluation of methods for estimating macroinvertebrate species richness using individual stones in tropical streams. Freshwater Biology, v. 46, n. 6, p. 711-721, 2001.

MITTERMEIER, R.A. et al. Hotspots revisited: earth's biologically richest and most endangered terrestrial ecoregions. Mexico: CEMEX, Agrupación Sierra Madre, 2004. 392 p.

MORELLATO, L.P.C.; HADDAD, C.F.B. Introduction: the Brazilian Atlantic Forest. Biotropica, v. 32, n. 4b, p 786-792, 2000.

NOGUEIRA, C.C. Diversidade e padrões de distribuição da fauna de lagartos do Cerrado. 2006. 295 f. Tese (Doutorado em Ecologia) Instituto de Biociências, Universidade de São Paulo, São Paulo.

;) BARBO, F.E.; FERRAREZZI, H. Redescription of Apostolepis albicollaris Lema, 2002, with a key for the species groups of the genus Apostolepis (Serpentes: Dipsadidae: Elapomorphini). South American Journal of Herpetology, v. 7, n. 3, p. 213-225, 2012.

OLIVEIRA, R.J. Variação da composição florística $e$ da diversidade alfa das florestas atlânticas no estado de São Paulo. 2006. 144 f. Tese (Doutorado em Biologia Vegetal) Instituto de Biologia, Universidade Estadual de Campinas, Campinas.

OLIVEIRA-FILHO, A.T.; FONTES, M.A.L. Patterns of floristic differentiation among Atlantic forests in Southeastern Brazil and the influence of climate. Biotropica, v. 32, n. 4b, p. 793-810, 2000.

PHILLOTT, A.D. et al. Toe-clipping as an acceptable method of identifying individual anurans in mark recapture studies. Herpetological Review, v. 38, n. 3, p. 305-308, 2007.

PRADO, D.E. Seasonally dry forests of Tropical South America: from forgotten ecosystems to a new phytogeographic unit. Edinburgh Journal of Botany, v. 57, n. 3, p. 437-461, 2000.
RIBEIRO, M.C. et al. The Brazilian Atlantic Forest: a shrinking biodiversity hotspot. In: ZACHOS, F.E.; HABEL, J.C. (Ed.). Biodiversity hotspots: distribution and protection of conservation priority areas. Heidelberg: Springer, 2011. p. 405-434.

RIBEIRO, S.L.B.; SANTOS JR., A.P.; VAZ-SILVA, W. Reptilia, Squamata, Amphisbaenidae, Amphisbaena mertensi: distribution extension, new state record, geographic distribution map. Check List, v. 3, n. 2, p. 84-87, 2007.

RIBEIRO-JÚNIOR, J.W.; BERTOLUCI, J. Anuros do cerrado da Estação Ecológica e da Floresta Estadual de Assis, sudeste do Brasil. Biota Neotropica, v. 9, n. 1, p. 207-216, 2009.

ROLIM, D.C. Estrutura da comunidade de anfíbios da região de Bauru, SP. 2013. 137 f. Tese (Doutorado em Zoologia) - Instituto de Biociências, Universidade Estadual Paulista, Botucatu.

et al. Amphibia, Anura, Cycloramphidae, Proceratophrys moratoi (Jim and Caramaschi, 1980): distribution extension and new altitudinal record in state of São Paulo, Brazil. Check List, v. 6, n. 4, p. 576-578, 2010.

ROSSA-FERES, D.C. et al. Anfíbios do estado de São Paulo, Brasil: conhecimento atual e perspectivas. Biota Neotropica, v. 11, n. 1a, p. 1-19, 2011.

SANTOS, T.G. et al. Anurans of a seasonally dry tropical forest: Morro do Diabo State Park, São Paulo state, Brazil. Journal of Natural History, v. 43, n. 15-16, p. 973-993, 2009.

SÃO PAULO (Estado). Decreto Estadual no 60.133, de 7 de fevereiro de 2014. Declara as espécies da fauna silvestre ameaçadas de extinção, as quase ameaçadas e as deficientes de dados para avaliação no Estado de São Paulo e dá providências correlatas. Diário Oficial do Estado de São Paulo, Poder Executivo, v. 124, n. 27, 8 fev. 2014. Seção 1, p. 25-32.

SAZIMA, I. Natural history of the jararaca pitviper, Bothrops jararaca, in southeastern Brazil. In: CAMPBELL, J.A.; BRODIE, E.D. (Ed.). Biology of the pitvipers. Tyler: Selva, 1992. p. 199-216. 
ARAUJO, C.O. Herpetofauna da Estação Ecológica de Bauru, São Paulo, Brasil.

SAZIMA, I.; HADDAD, C.F.B. Répteis da Serra do Japi: notas sobre história natural. In: MORELLATO, L.P.C. (Ed.). História natural da Serra do Japi: ecologia e preservação de uma área florestal no Sudeste do Brasil. Campinas: Editora Unicamp: FAPESP, 1992. p. 212- 236.

SCOTT JR., N.J.; WOODWARD, B.D. Surveys at breeding sites. In: HEYER, W.R. et al. (Ed.). Measuring and monitoring biological diversity: standard methods for amphibians. Washington, D.C.: Smithsonian Institution Press, 1994. p. 118-125.

SEGALLA, M.V. et al. Brazilian amphibians: list of species. Herpetologia Brasileira, v. 5, n. 2, p. 34-46, 2016.

SERRANO FILHO, S. Diversidade e distribuição dos lagartos de uma área de ecótono entre Cerrado e Mata Atlântica, no sudeste do Brasil. 2012. 53 f. Dissertação (Mestrado em Biologia Animal) Instituto de Biociências, Letras e Ciências Exatas, Universidade Estadual Paulista, São José do Rio Preto.

SILVA, F.R. Evaluation of survey methods for sampling anuran species richness in the Neotropics. South American Journal of Herpetology, v. 5, n. 3, p. 212-220, 2010.

SILVANO, D.L. Distribuição e conservação de anfíbios no Cerrado em cenários atuais e futuros. 2011. 121 f. Tese (Doutorado em Ecologia) - Instituto de Ciências Biológicas, Universidade de Brasília, Brasília, DF.

SILVEIRA, A.L.; BRITES, V.L.C.; VALINHAS, R.V. First record of Amphisbaena mertensi Strauch, 1881 (Squamata: Amphisbaenidae) in Minas Gerais state, Brazil. Check List, v. 8, n. 1, p. 161-163, 2012.

SILVEIRA, L.F. et al. Para que servem os inventários de fauna? Estudos Avançados, v. 24, n. 68, p. 173-207, 2010.

SOUZA, F.M. et al. Vegetação. In: ALMEIDA, E.R.; TONIATO, M.T.Z.; DURIGAN, G. (Ed.). Plano de Manejo da Estação Ecológica de Bauru. São Paulo: Fundação Florestal/SEMA, 2010. p. 96-110.
THOMÉ, M.T.C. Diversidade de anuros e lagartos em fisionomias de Cerrado na região de Itirapina, Sudeste do Brasil. 2006. $52 \mathrm{f}$. Dissertação (Mestrado em Ecologia) - Instituto de Biociências, Universidade de São Paulo, São Paulo.

UETANABARO, M. et al. Guia de campo dos anuros do Pantanal e planaltos de entorno. Campo Grande: UFMS; Cuiabá: UFMT, 2008. $196 \mathrm{p}$.

VALDUJO, P.H. et al. Anfíbios da Estação Ecológica Serra Geral do Tocantins, região do Jalapão, estados do Tocantins e Bahia. Biota Neotropica, v. 11, n. 1, p. 251-262, 2011.

et al. Anuran species composition and distribution patterns in Brazilian Cerrado, a neotropical hotspot. South American Journal of Herpetology, v. 7, n. 2, p. 63-78, 2012.

VANZOLINI, P.E.; WILLIAMS, E.E. South American anoles: the geographic differentiation and evolution of the Anolis chrysolepis species group (Sauria, Iguanidae). Arquivos de Zoologia (São Paulo), v. 19, n. 3-4, p. 1-298, 1970.

VASCONCELOS, T.S.; ROSSA-FERES, D.C. Diversidade, distribuição espacial e temporal de anfíbios anuros (Amphibia, Anura) na região noroeste do estado de São Paulo. Biota Neotropica, v. 5, n. 2, p. 1-14, 2005.

VERDADE, V.K. et al. A leap further: the Brazilian Amphibian Conservation Action Plan. Alytes, v. 29, n. 1-4, p. 28-43, 2012.

WALTHER, B.A.; MOORE, J.L. The concepts of bias, precision and accuracy, and their use in testing the performance of species richness estimators, with a literature review of estimator performance. Ecography, v. 28, n. 6, p. 815-829, 2005.

WERNECK, F.P.; COLLI, G.R. The lizard assemblage from Seasonally Dry Tropical Forest enclaves in the Cerrado biome, Brazil, and its association with the Pleistocenic Arc. Journal of Biogeography, v. 33, n. 11, p. 1983-1992, 2006. 
ARAUJO, C.O. Herpetofauna da Estação Ecológica de Bauru, São Paulo, Brasil.

WERNECK, F.P. et al. Revisiting the historical distribution of Seasonally Dry Tropical Forests: new insights based on palaeodistribution modelling and palynological evidence. Global Ecology and Biogeography, v. 20, n. 2, p. 272-288, 2011.

ZAHER, H. et al. Répteis do Estado de São Paulo: conhecimento atual e perspectivas. Biota Neotropica, v. 11, n. 1a, p. 1-15, 2011. 
ARAUJO, C.O. Herpetofauna da Estação Ecológica de Bauru, São Paulo, Brasil.

Apêndice 1. Linhas de armadilhas de interceptação e queda e ambientes aquáticos amostrados na Estação Ecológica de Bauru, SP. Fitofisionomias: floresta estacional semidecidual montana (FESM); floresta estacional semidecidual aluvial (FESA); ecótono Cerrado/floresta estacional (C/FE).

Appendix 1. Pitfall traps lines and aquatic sites sampled at the Estação Ecológica de Bauru, São Paulo state, Brazil. Phytophysiognomies: seasonal semideciduous montane forest (FESM); seasonal semideciduous alluvial forest (FESA); ecotone Savanna/seasonal forest (C/FE).

\begin{tabular}{|c|c|c|}
\hline Linha de armadilha/ambiente aquático & Fitofisionomia & Coordenada geográfica (SAD 69) \\
\hline 1 & FESM & $22^{\circ} 13^{\prime} 46^{\prime \prime} \mathrm{S} / 49^{\circ} 04^{\prime} 52^{\prime \prime} \mathrm{O}$ \\
\hline 2 & FESM & $22^{\circ} 14^{\prime} 08^{\prime \prime} \mathrm{S} / 49^{\circ} 05^{\prime} 08^{\prime \prime} \mathrm{O}$ \\
\hline 3 & FESM & $22^{\circ} 14^{\prime} 15^{\prime \prime} \mathrm{S} / 49^{\circ} 04^{\prime} 53^{\prime \prime} \mathrm{O}$ \\
\hline 4 & FESM & $22^{\circ} 13^{\prime} 58^{\prime \prime} \mathrm{S} / 49^{\circ} 05^{\prime} 03^{\prime \prime O}$ \\
\hline 5 & FESM & $22^{\circ} 14^{\prime} 18^{\prime \prime} \mathrm{S} / 49^{\circ} 04^{\prime} 45^{\prime \prime} \mathrm{O}$ \\
\hline 6 & FESM & $22^{\circ} 13^{\prime} 56^{\prime \prime} \mathrm{S} / 49^{\circ} 05^{\prime} 04^{\prime \prime} \mathrm{O}$ \\
\hline 7 & FESM & $22^{\circ} 14^{\prime} 07^{\prime \prime} \mathrm{S} / 49^{\circ} 05^{\prime} 30^{\prime \prime} \mathrm{O}$ \\
\hline 8 & FESM & $22^{\circ} 14^{\prime} 17^{\prime \prime} \mathrm{S} / 49^{\circ} 05^{\prime} 27^{\prime \prime O}$ \\
\hline 9 & FESM & $22^{\circ} 13^{\prime} 47^{\prime \prime} \mathrm{S} / 49^{\circ} 05^{\prime} 53^{\prime \prime} \mathrm{O}$ \\
\hline 10 & FESM & $22^{\circ} 13^{\prime} 47^{\prime \prime} \mathrm{S} / 49^{\circ} 05^{\prime} 22^{\prime \prime} \mathrm{O}$ \\
\hline 11 & $\mathrm{C} / \mathrm{FE}$ & $22^{\circ} 13^{\prime} 51^{\prime \prime} \mathrm{S} / 49^{\circ} 05^{\prime} 40^{\prime \prime} \mathrm{O}$ \\
\hline I - Lagoa temporária na borda de mata & FESM & $22^{\circ} 14^{\prime} 11^{\prime \prime} \mathrm{S} / 49^{\circ} 05^{\prime} 12^{\prime \prime} \mathrm{O}$ \\
\hline II - Poça temporária no interior de mata & FESM & $22^{\circ} 14^{\prime} 09^{\prime \prime} \mathrm{S} / 49^{\circ} 05^{\prime} 11^{\prime \prime} \mathrm{O}$ \\
\hline III - Poça temporária no interior de mata & FESM & $22^{\circ} 14^{\prime} 08^{\prime \prime} \mathrm{S} / 49^{\circ} 05^{\prime} 11^{\prime \prime} \mathrm{O}$ \\
\hline IV - Riacho no interior de mata & FESM & $22^{\circ} 13^{\prime} 59^{\prime \prime} \mathrm{S} / 49^{\circ} 05^{\prime} 08^{\prime \prime} \mathrm{O}$ \\
\hline V - Riacho no interior de mata & FESM & $22^{\circ} 14^{\prime} 05^{\prime \prime} \mathrm{S} / 49^{\circ} 05^{\prime} 30^{\prime \prime} \mathrm{O}$ \\
\hline VI - Córrego na borda da mata & FESA & $22^{\circ} 14^{\prime} 19^{\prime \prime} \mathrm{S} / 49^{\circ} 05^{\prime} 01^{\prime \prime} \mathrm{O}$ \\
\hline VII - Córrego na borda da mata & FESA & $22^{\circ} 14^{\prime} 16^{\prime \prime} \mathrm{S} / 49^{\circ} 05^{\prime} 12^{\prime \prime} \mathrm{O}$ \\
\hline VIII - Córrego na borda da mata e poças temporárias & FESA & $22^{\circ} 14^{\prime} 20^{\prime \prime} \mathrm{S} / 49^{\circ} 05^{\prime} 30^{\prime \prime} \mathrm{O}$ \\
\hline IX - Brejo na borda de mata & FESA & $22^{\circ} 14^{\prime} 15^{\prime \prime} \mathrm{S} / 49^{\circ} 05^{\prime} 31^{\prime \prime} \mathrm{O}$ \\
\hline
\end{tabular}


ARAUJO, C.O. Herpetofauna da Estação Ecológica de Bauru, São Paulo, Brasil.

Apêndice 2. Anfíbios e répteis coletados na Estação Ecológica de Bauru, SP e depositados na Coleção de Anfíbios do Instituto de Biociências da Universidade Estadual Paulista, Rio Claro (CFBH) e Coleção Herpetológica "Alphonse Richard Hoge", Instituto Butantan, São Paulo (IBSP e CRIB).

Appendix 2. Amphibians and reptiles collected at the Estação Ecológica de Bauru, São Paulo state, Brazil and deposited in the Coleção de Anfíbios do Instituto de Biociências da Universidade Estadual Paulista, Rio Claro (CFBH) e Coleção Herpetológica “Alphonse Richard Hoge”, Instituto Butantan, São Paulo (IBSP and CRIB).

CFBH: Chiasmocleis albopunctata (19997-20003); Dendropsophus minutus (19995); Dendropsophus nanus (19992-19994, 19996); Elachistocleis cesarii (20004-20008); Hypsiboas albopunctatus (19788-19789); Hypsiboas faber (19755); Hypsiboas lundii (19756); Leptodactylus fuscus (19759-19760); Leptodactylus labyrinthicus (19749); Leptodactylus latrans (19761-19763); Leptodactylus mystaceus (19781-19787, 20014); Leptodactylus mystacinus (19764-19768); Leptodactylus podicipinus (19987-19991); Physalaemus cuvieri (20009-20013, 20015-20017); Physalaemus nattereri (19769-19774); Rhinella ornata (19775-19780); Rhinella schneideri (19750-19754); Scinax fuscovarius (19790-19791); Scinax similis (19792-19793); Trachycephalus typhonius (19757-19758).

IBSP: Apostolepis dimidiata (76919); Bothrops jararaca (76918).

CRIB: Amphisbaena mertensii (1310-1312); Norops brasiliensis (0699-0701). 